\title{
A Gênese Afetiva da Emoção e da Cognição na Consciência
}

\section{The affective genesis of emotion and cognition in the consciousness}

Resumo: Logo após o início da psicologia científica o estudo sobre a consciência foi colocado à margem devido a sua obscuridade e dificuldade em torná-lo objeto de pesquisa. Com o surgimento e desenvolvimento das ciências cognitivas esse tema retorna e com ele é trazida ao debate a importância das emoções no processo cognitivo. Nesse artigo pretendemos analisar a contribuição de F. Varela e N. Depraz sobre a teoria do afeto mostrando pontos de aproximação e afastamento das concepções de E. Husserl e W. James. Discutimos também alguns aspectos da teoria de G. Simondon onde encontramos ressonâncias na abordagem do problema. $\mathrm{Na}$ interlocução entre esses diversos autores concluímos que o domínio afetivo se coloca como elemento genético das emoções e dos conteúdos cognitivos do sujeito.

Palavras-chave: Afeto. Emoção. Cognição. Subjetividade.

Abstract: Soon after the scientific psychology beginning the consciousness' study was put to the margin due its obscurity and difficulty in becoming it research object. With the appearance and development of the cognitive sciences this subject returns and with it is brought to the debate the importance of the emotions in the cognitive process. In this article we intend to analyse the F. Varela and N. Depraz contribution about affective's theory showing points of approach and remoteness at the E. Husserl and W. James conceptions. We also discuss some aspects of the G. Simondon theory where we find resonance in the problem's approach. In the interlocution between these various authors we understand the affective domain as a genetic element of emotions and cognitive contents of the subject.

Keyword: Affect. Emotion. Cognition. Subjectivity.
ROCHA, Jerusa Machado A Gênese Afetiva da Emoção e da Cognição na Consciência. Informática na Educação: teoria \& prática, Porto Alegre, v. 12, n. 2, p. 93-104, jul./dez. 2009.

\author{
Jerusa Machado Rocha \\ Hospital Azevedo Lima
}

\section{I ntrodução}

A pesquisa em psicologia desde seus primórdios tem privilegiado uma separação entre o domínio cognitivo e emotivo. A emoção partiria de um modelo adaptativo e evolutivo, como um fenômeno predominantemente somático, enquanto a cognição teria sua fonte na capacidade humana de abstrair e representar. A emoção humana é considerada como um sinal de descontrole, em que uma dimensão instintiva e irracional é ativada. Esse impulso deveria, portanto ser controlado ou dominado pela inteligência. Seguindo esse modelo nossa tradição científica considera que o conhecimento atinge seu grau máximo na inteligência abstrata. Essa tradição está associada à tendência em imaginar que poderíamos ter cognição sem qualquer tonalidade emocional. Assim, as flutuações emocionais que acompanham e atravessam pensamentos e percepções cotidianas foram consideradas por uma grande parte da psicologia cognitiva como um colorido ou um mero suplemento que se adiciona à idéia.

A importância da emoção nos estudos da cognição surge para os pesquisadores das ciências cognitivas após se debruçarem sob o difícil problema da consciência. A partir da década de 1990, após o desenvolvimento de novas tecnologias para a pesquisa da mente e do 
cérebro, retorna o interesse das ciências cognitivas por problemas que foram considerados difíceis ou menos importantes. Cientistas que nas últimas décadas estiveram voltados apenas para os aspectos cognitivos da mente, começam a privilegiar o entendimento das emoções em sua relação com a cognição. Problema que logo após o início da psicologia científica de W. Wundt foi colocado à margem, ou deslocado e traduzido em outros problemas, sobretudo no behaviorismo, devido a sua obscuridade e dificuldade de objetivação, não se enquadrando nos moldes do fazer científico do laboratório de psicologia experimental.

Devido à dominância do behaviorismo na psicologia, o problema do sujeito humano era visto como pouco mais do que uma máquina estímulo-resposta. A pobreza desse projeto, afirma Sutherland (2001) foi o principal motivo que conduziu à chamada revolução cognitiva. Entretanto, a inteligência artificial não avançou muito, porque não fez muito mais do que substituir a máquina $\mathrm{S}-\mathrm{R}$ pela máquina de Turing - calculadora simbólica que constituiu o modelo do pensamento simbólico presente no cognitivismo computacional. A mente passa a ser concebida como tal máquina: "Toda função calculável mecanicamente é calculável por uma máquina de Turing " (DUPUY, 1995, p. 31). O estudo sobre a consciência passa a ser relevante nas Ciências Cognitivas quando o clássico programa da Inteligência Artificial mostra suas falhas ${ }^{1}$. O foco muda então da lógica matemática para a neurociência e para a biologia evolutiva. No entanto, o estudo sobre a consciência e a emoção se volta quase que exclusivamente para a pesquisa do funcionamento cerebral. Nesse contexto Francisco Varela, biólogo do conhecimento, propõe como método de pesquisa para o estudo da consciência a neurofenomenologia², uma circulação

1 A crítica se dirige ao paradigma computacionalista segundo o qual o conhecimento opera através de regras do tipo lógico para a manipulação simbólica. As pesquisas da IA nas primeiras décadas basearamse nesse paradigma (IA Forte). Assim, direcionaram seus esforços para a resolução de problemas gerais procurando igualar a inteligência da máquina à de um perito altamente treinado. Esse objetivo foi fracassado por se ter subestimado a complexidade do problema da aquisição de conhecimento (VARELA, 2003).

2 A neurofenomenologia é um método para a pesquisa da consciência, cujo objetivo é estudá-la a partir da experiência nela mesma e em constante tensão com as atuais pesquisas em neurociência. Esse método é explorado em Varela (1999). e um confronto permanente entre os níveis de experiência em primeira pessoa, sob redução fenomenológica, e os estudos em neurociência, ou seja, em terceira pessoa (VARELA, 1997). Os depoimentos acerca da experiência, que haviam sido exterminados dos estudos científicos da psicologia (sobretudo pelos behavioristas), são retomados de forma cuidadosa nesse movimento de busca e criação de novos modelos científicos. Varela (1997) institui como marco decisivo para uma mudança nas pesquisas neurocientíficas o trabalho do filósofo californiano David Chalmers - O Difícil Problema da Consciência - apresentado num congresso realizado em Tucson em 1994, onde argumenta ser impossível estudar a consciência confiando apenas em máquinas de alta tecnologia para sondar o cérebro e ignorando o que as pessoas estavam sentindo.

Em suas pesquisas sobre o tema da consciência, Varela aponta a relevância de um domínio que é pré-pessoal e pré-reflexivo, o das tonalidades afetivas. Ele concebe a consciência como constituída no tempo, o qual exprime um impulso que é formador da própria subjetividade. A subjetividade, sendo construída no tempo e pelo tempo, não possui uma identidade imóvel, mas é um sair de si, uma abertura para a alteridade. O tempo é a base para a constituição da consciência, uma vez que não é ela que contém o tempo como uma categoria psicológica constituída, mas, ao contrário, a consciência temporal se apresenta como um substrato elementar ou fundamento da consciência psicológica (VARELA, 1997). A consciência temporal é explicada aqui como o substrato último da consciência, onde a redução pode ser realizada. Ou seja, a consciência temporal é movimento, pois está imersa no fluxo do tempo. Nesse artigo propomos pensar o domínio cognitivo e emotivo como constituídos a partir de um plano afetivo genético, substrato elementar ou fundamento para a constituição da consciência psicológica tomando como referência os trabalhos de Francisco Varela e Natalie Depraz. Apresentaremos ainda as ressonâncias sobre a questão em Gilbert Simondon na abordagem da afetoemotividade.

\section{A Cognição Encarnada ou En- Ativa}

Ao contrário da hipótese cognitivista, a qual baseia a cognição no tratamento da informa- 
ção mediante a manipulação de símbolos por regras lógicas - em que o pensamento seria apenas um processamento simbólico representado na mente -, para Varela a cognição é antes de tudo corporal. Conhecemos com o corpo inteiro e não apenas com a mente. A cognição não é formulada aqui em termos de leis ou princípios invariantes, conforme a concepção cognitivista. Ela é viva, mais do que abstrata. O sistema vivo é, por definição, um sistema cognitivo (KASTRUP, 1999). Agir, tomar parte no mundo institui um ato criador em que sujeito e mundo emergem. Varela parte da biologia para pensar a cognição e daí se estabelece de imediato um domínio que está aquém e além do humano, ou seja, a função cognitiva é colocada em outro plano que não privilegia mais a mediação representativa, intelectualizada. Poderíamos dizer que a cognição nesse caso está colocada num plano ontológico, e não apenas psicológico, na medida em que ser, fazer e conhecer forma uma unidade e se constitui num único ato. Assim, Varela (2003) aposta numa mudança epistêmica radical no seio das ciências cognitivas. A historicidade $e$ o contexto não são mais considerados como ruídos ou obstruções na busca por uma essência verdadeira: “[ . . . ] as próprias unidades de conhecimento são fundamentalmente concretas, corporificadas, incorporadas, vividas" (VARELA, 2003, p. 72). A ênfase é colocada mais no processo do que no resultado final. Em cada ato cognitivo existe uma infinidade de subprocessos competindo, até que finalmente emerge um comportamento definitivo, algo de concreto e específico. Esses subprocessos surgem a partir de perturbações, breakdowns ${ }^{3}$, e nos fazem construir novas disposições para a ação. Não se pode especificar uma causa unidirecional e hierárquica para a constituição do sujeito, mas antes, o entrecruzamento de múltiplos vetores, numa constituição em rede:

[ . . . ] na realidade um organismo não é uma coisa, mas sim o locus onde ocorrem todas as emergências de muitos selfless selves, em muitos níveis, celular, imunológico, neuronal, lingüístico, social: e todos esses ocorrem simultaneamente sem que haja um lugar preferencial. Logo a experiência de um sujeito humano não se situa em um lugar preferencial, mas está em toda parte (VARELA, 1993, p. 97).

3 Breakdown é o termo utilizado por Varela (2003) para se referir a pequenos momentos em que experiências perturbadoras ocasionam uma súbita ruptura no modo como interagimos com o mundo, e que somos, então, forçados a problematizar.
Com base em suas pesquisas Varela (VARELA, F; THOMPSON, E; ROSCH, E; 2003) nota o quanto é importante para o processo de aprendizagem - tanto em animais como em humanos - que haja uma participação ativa por parte do aprendiz. Partindo de experiências simples, como o estudo da percepção, ele observa que é por meio de esquemas sensório-motores que surgem as estruturas cognitivas da vida humana, e que essa cognição é inseparável de uma ação cognitiva, o par saber-fazer é indissociável. Portanto, são as ações corporizadas que formam a cognição. Dessa forma Varela (VARELA, F; THOMPSON, E; ROSCH, E; 2003) não supõe uma separação entre, por um lado, um mundo pré-definido, estático, em vias de ser conhecido, e por outro as estruturas cognitivas formais. O mundo só é conhecido enquanto efetivado (enacted) agido, mediante a história das conexões estabelecidas por cada um e o eixo temporal presente na efetuação de cada comportamento cognitivo.

Esse eixo temporal assegura a novidade de cada momento cognitivo, assim como a possibilidade da inventividade na cognição. Como não existe um mundo definido de antemão, Varela falará de micromundos e microidentidades. O conhecimento será sempre construído a partir desses pequenos domínios que se configuram a cada ocasião.

\section{A Consciência Temporal na Gênese do Processo Cognitivo- Emotivo}

A partir da psicologia de William James e da fenomenologia genética de Edmund Husserl, Varela (1997) concebe a consciência temporal como um bloco de duração. Entretanto, James, em seus últimos trabalhos, abandona a noção de consciência enquanto uma substância, para concebê-la como um puro fluxo, imanente à experiência, material físico-mental, sem eu e sem forma: realidade intermediária. Esses dois níveis de consciência em James serão tratados no item a seguir. Com base também no último trabalho de Husserl, Varela (1997) afirma que todas as formas de atividade mental baseiamse na temporalidade.

A partir desses dois autores, Varela (1997) distingue então três níveis temporais na composição da consciência: 1) O primeiro, próximo às concepções mais usuais de tempo, tal como utilizadas na física clássica, nas ciências 
computacionais, e na psicologia experimental. Ocorre quando a consciência refere-se a objetos temporais e eventos no mundo; 2) O segundo decorre de um ato de redução fenomenológica. É o tempo interno ou imanente aos atos de consciência; 3) O terceiro nível é o mais elementar, sendo constitutivo dos outros dois primeiros, onde a distinção entre interno e externo não é mais possível. É o que Husserl (apud VARELA, 1997, p. 20) chama “[ . . . ] tempo absoluto constituindo fluxos de consciência4".

Varela é influenciado pela fenomenologia husserliana ${ }^{5}$ quando elabora sua concepção de consciência e também em sua proposta para uma teoria das emoções. Entretanto, na fase inicial dos trabalhos de Husserl, a emoção não é relevante para o domínio teórico ou cognitivo - veremos que o conceito de emoção sofrerá modificações diversas no avançar de sua teoria -, os atos perceptivos e categoriais são os que dão acesso ao conhecimento do objeto. As emoções (gefühle), enquanto atos não objetivantes, são fundadas sobre os atos objetivantes, que são primariamente perceptivos. Ou seja, o ato perceptivo não inclui as emoções num primeiro momento, apenas após o objeto formado. Depois da forma constituída, as emoções vão aparecer. Tais atos não objetivantes vão pertencer apenas ao campo prático, ético ou estético (DEPRAZ, 1999).

Assim, as emoções serão sempre segundas, ou derivadas do conhecimento prévio que temos do mundo. As emoções são avaliações, pois elas só aparecem após algum conhecimento ter sido estabelecido, quando sujeito e objeto já estão constituídos. Não há para a fenomenologia, ao menos nessa etapa de sua construção teórica, nenhum nível afetivo primordial que estabeleça contato com a exterioridade.

A teoria husserliana nesse momento difere da proposta de James (1979) explicitada nos Ensaios em Empirismo Radical. O conhecimento para Husserl é isento de qualquer impureza

4 A tradução dos textos cuja referência está em língua estrangeira é de nossa responsabilidade.

5 Como foge aos limites deste trabalho fazer uma exegese da obra de Husserl, mas apenas seguir os direcionamentos dos autores Varela e Depraz (2000) no que aproveitaram ou declinaram na teoria desse filósofo para construírem seus próprios trabalhos, nos restringimos aqui às citações e explicações que esses e outros autores trazem da filosofia husserliana. da afetividade. Ele se apóia num domínio transcendental que fornece condições para a gênese do conhecimento, liberada de toda matéria empírica. As condições puras são ligadas entre si por um ego transcendental e constituem um plano. "Assim Husserl pode pretender atingir verdadeiramente a experiência pura: 'O início é a experiência pura, e por assim dizer muda ainda' [ . . . ]" (LAPOU] ADE, 1997, p. 20). Entretanto, a expressão primeira da experiência pura em Husserl é a do eu sou cartesiano. Mas se o ego é a condição de direito, ele não pode ser objeto de nenhuma gênese. O que Husserl denomina de puro é diferente do que dizia James: "Puro significa precisamente que se estudam os vividos enquanto imanentes à consciência. As filosofias transcendentais se liberam da matéria empírica, mas conservam, entretanto, as formas herdadas da psicologia [ . . . ]" (LAPOUJADE, 1997, p. 21). James, ao contrário, abre uma terceira via e instaura uma experiência pura que não se reduz nem a uma pura matéria sensitiva, e que tampouco é constituída pelas formas de uma subjetividade pura. Diversamente da matéria empírica, a experiência pura é um material (stuff) que designa uma realidade que pode ser, ao mesmo tempo, física e mental: “Realidade intermediária que se estende entre o espírito e a matéria, lá onde elas se confundem estreitamente, mas a partir da qual, por outro lado, elas se distinguem, embora apenas virtualmente." (LAPOUJADE, 1997, p. 23). A consciência para James se confunde, nesse momento, com os objetos materiais dos quais são feitos os pensamentos.

A problemática afetiva ganhará relevo apenas num momento posterior, quando Husserl desenvolverá a fenomenologia genética, e dará importância à constituição primordial afetiva. Segundo Varela (1997), é um trabalho ainda pouco conhecido, por ter sido publicado posteriormente $^{6}$ numa edição crítica alemã que

6 Esse livro foi preparado por sua assistente Edith Stein, no ano de 1917, a partir de textos de seminários apresentados por ele em diversos anos (1901, 1905 e 1917). Entretanto, sua publicação foi adiada para que Husserl pudesse fazer novas revisões. Apenas em 1927, após discutir com Heidegger a iminente publicação de Sein und Zeit, Husserl decide retornar ao trabalho de Stein e enviá-lo a Heidegger, que adiciona pequenas modificações. O título de sua publicação original Vorlesungen über das innere Zeibewusstsein aus dem Jahre 1905 (Halle, 1928) foi traduzido para o inglês, por J. S. Churchill, como The Phenomenology of Internal Time Consciousness, em 
inclui apêndices inéditos. É nesta fase da obra de Husserl que Varela e Depraz (2000) irão buscar os fundamentos para a teoria proposta de uma cognição imanente ao campo afetivo. Embora Varela utilize os textos de Husserl, veremos que discorda dele em alguns aspectos. Varela busca em Husserl e James um solo onde possa construir sua própria teoria.

\section{Papel do Afeto e do Tempo na Perspectiva da Enação}

Os dois níveis de consciência em James (1979) são o puro presente e o fluir temporal no sentido passado-futuro. Se por um lado existe uma unidade no presente, o que nos permite descrever onde reside nossa consciência básica, por outro, esse momento da consciência é inseparável de um fluxo. São os dois aspectos complementares da consciência temporal, apresentada por James (1979) em Princípios de Psicologia (capítulo IX - O Fluxo do Pensamento).

James (1979) toma como exemplo do fluxo temporal condensado no presente a forma pela qual Mozart compõe. Ele inicia sua obra por fragmentos e porções que surgem gradualmente em sua mente. Até que, com a alma aquecida, a coisa cresce cada vez mais, vai se alargando e ficando mais clara. Finalmente, ela fica quase acabada em sua cabeça - mesmo se for uma peça extensa - , de tal forma, que ele pode ver o todo por meio de um simples relance. Assim, ele não a ouve em sua mente como uma sucessão, mas toda de uma única vez. A esse propósito, afirma James: “Grandes pensadores têm vastos relances premonitórios de esquemas de relação entre termos, que dificilmente, mesmo com imagens mentais, entram na mente, tão rápido é o processo total." (JAMES, 1979, p. 143). E continua adiante: "Quando muito descansadas, nossas mentes carregam um horizonte imenso com elas. A imagem presente lança sua perspectiva longe, diante de si, irradiando antecipadamente as regiões em que se fundam os pensamentos

1966. Em 1966, Rudolf Boehm produz uma edição crítica disponível como Husserlianna X, Zur Phänomenologie des inneren Zeibewusstsein (PZB). Essa edição fornece apêndices e esboços não publicados, além de uma ampla seleção de seus escritos com uma análise cronológica cuidadosa da adição de 1928 (VARELA, 1997). Essa edição foi a fonte principal para Varela na confecção do artigo sobre a consciência. ainda não nascidos [ . . . ]" (JAMES, 1979, p. 143).

O tempo apresenta-se aqui como completamente diferente do tempo linear de um relógio, pois em vez de uma seqüência linear, ele possui uma textura, donde o termo utilizado por James (1979), specious present. O conteúdo focado no presente constitui um centro que é limitado por um horizonte ou borda. Tal horizonte já é passado e ao mesmo tempo se projeta em direção a um próximo momento. Esses horizontes móveis englobam os três aspectos da temporalidade: esse momento extremo que era vivenciado como presente desliza em direção a um imediatamente presente passado. Para Varela, a textura que compõe o presente não possui apenas uma localização no tempo, mas possui também uma qualidade vivida. Essa qualidade configura-se como o espaço onde residimos, mais do que um ponto por onde um objeto passa transitoriamente.

Husserl distingue consciência de impressões de consciência de representações. Numa impressão, um objeto é originalmente constituído, e dado como presente. A representação, por sua vez, representa um objeto já dado para a impressão. O novo sempre aparece numa impressão, ou seja, como uma apresentação, enquanto a memória evocativa aparece como uma re-apresentação.

A retenção conserva fases do mesmo ato perceptual, sem se confundir com a representação. Desse modo, a retenção não é a mesma coisa que memória evocativa. Ela é o passado retido, mas não representado. Podemos dizer que é o passado em ato que carregamos tensionados durante a execução de uma atividade, como na audição de uma música. Nada faria sentido se, ao passarmos de uma frase musical a outra, não carregássemos a frase anterior retida, mas não de forma imaginada ou representada. A protensão é a contínua e ininterrupta passagem para um futuro, uma abertura que não carrega em si nenhuma forma, não contendo também nenhuma representação, o que Husserl chama de constituição vazia.

Retenção e protensão são as maneiras como Husserl designa essa dinâmica da impressão. A retenção conserva fases do mesmo ato perceptual, de modo que ele não se distingue da experiência do presente: “[ . . . ] seu contato direto com percepções anteriores, ao construir a percepção de qualquer instante dado, contém entidades que aparecem como 
temporalidade estendida." (VARELA, 1997, p. 12). Retenção é, portanto, o atributo do ato mental que conserva fases do mesmo ato perceptual, não como representação, mas como impressão, como presença. Outro exemplo da retenção é o momento imediato da leitura de um livro. Para que a leitura desse texto seja compreendida, é necessário retermos o sentido imediatamente lido à medida que a leitura avança. A retenção é o contato direto com percepções anteriores numa percepção atual, ou seja, uma temporalidade estendida da percepção imediata. De forma similar, a protensão se dirige ao futuro, numa tentativa de buscar contato com as percepções que virão. Nos textos de Husserl, a protensão não é extensivamente analisada, mas Varela (1997) acredita que ela assume, mesmo que de forma implícita, certa simetria com a retenção, como se a mesma estrutura para o passado pudesse ser lançada em direção ao futuro. É uma antecipação do que está para vir, como numa melodia em que intuímos qual será a próxima nota. Embora Varela (1997) retome os conceitos de Husserl de retenção e protensão, discorda que estes sejam simétricos.

Nas duas pontas que compõem o presente vivo, ou seja, a da retenção que acumula o passado e a da protensão que se lança ao futuro, Varela (1997) vai privilegiar a protensão como a via de acesso ao estudo do afeto. Entretanto, ele a redimensiona, propondo uma dessimetria entre a retenção e a protensão. Por dois motivos principais: 1) Primeiramente porque, embora Husserl não tenha desenvolvido melhor o tema, Varela percebe que o novo sempre se expande com o afeto e com a tonalidade emocional que acompanha o fluxo: “A protensão não é um tipo de expectativa que pode ser compreendida como previsível, mas uma abertura que é capaz de self-movement, um indeterminado preste a se manifestar [ . . . ]" (VARELA, 1997, p. 26). Nessa qualidade, esclarece Varela (1997, p. 26), “[ . . . ] ela fornece o elo natural com o afeto, ou, mais pertinentemente, com alguma forma de self-affectedness ${ }^{7}$ [ . . . ]"; 2) Em segundo lugar porque, baseada na concepção mesma de Husserl, a retenção tem a estrutura de um continuum,

7 Preferimos manter no original os termos automovimento (self-moviment) e auto-afetividade (selfaffectedness) por serem expressões criadas pelo autor. que vai se reconfigurando a cada momento, enquanto a protensão se configura como um domínio limitado, no sentido em que não pode antecipar o novo, o que está para vir. Ou seja, enquanto as linhas retencionais se modificam retroativamente, as linhas da protensão não podem se lançar ao futuro indefinidamente (VARELA, 1997). Veremos que esse domínio que se configura para Husserl como aparentemente limitado, por carregar expectativas que se baseiam no passado, pode ser muito fértil, na medida em que, por outro lado, pertence ao campo do imprevisível, abarcando múltiplos possíveis. O conceito de breakdown em Varela carrega essa abertura.

Portanto, foi a partir do conceito de protensão em Husserl que Varela (1997) começou a desenvolver sua própria teoria do afeto. Husserl observa que, ao ouvirmos uma melodia, o som nos afeta diferentemente, na medida em que cria linhas de retenção, numa tendência atencional. Varela considera, então, que o afeto fornece uma disposição, que é marcada por intensidades graduais: "Esse efeito de temporalização coloca a protensão na zona central [ ... . ]" (VARELA, 1997, p. 26).

Pode se encontrar referência, em algumas notas de Husserl, ao afeto como esse aspecto primordial, presente nos primeiros dias de um recém-nascido, que ele denomina como intencionalidade instintiva. Nessas anotações, o afeto é considerado uma não-forma que constitui o self por ele mesmo. Ele existe antes de ser plenamente consciente para mim: "Somos afetados antes mesmo de sabermos que somos afetados. É nesse sentido que o afeto pode ser dito primordial." (VARELA, 2002, p. 131).

A aparente contradição entre se haveria uma impressão original no tempo que seria colorida pelo afeto, ou, ao contrário, se haveria uma primazia do afeto que seria subjacente à temporalidade é colocada por Varela em outros termos que procuram desfazer tal contradição: “Nós procuramos uma síntese não-dual onde o afeto seria tanto constitutivo do self, como, ao mesmo tempo, conteria uma radical abertura, ou um inesperado em relação ao que irá ocorrer." (VARELA, 1997, p. 27). Essa questão é fundamental para colocar o problema da imanência cognição-emoção no plano afetivo, pois ele coloca a temporalidade e sua radical abertura no plano de constituição do self.

O problema do afeto e do tempo é explorado por Varela no contexto de um envolvimen- 
to ativo no mundo, segundo a perspectiva da enação. Ele aborda o afeto enquanto disposição, pesquisando sua qualidade disposicional (dispositional quality) em diversas gradações. O acoplamento $^{8}$ desempenha um papel central aqui: “Acoplamento é uma prontidão ou tendência disposicional para ação num campo mais largo, uma ontological readiness ${ }^{9}$, isto é, uma expectativa para o modo no qual o mundo irá mostrar-se" (VARELA, 2002, p.132). Para se ter transparência numa ação é preciso adquirir uma habilidade, fruto de uma aprendizagem. Acoplamento tem, portanto, estreita relação com o hábito, a recorrência de nossas vidas: "Aprender uma habilidade é um exemplo protótipo da aquisição de transparência para a ação." (VARELA, 2002, p. 132).

A ocorrência de um breakdown, de uma perda de fluidez no acoplamento - que pode ocorrer de múltiplas formas diferentes, e em diversos graus - , abre uma panóplia de tonalidades afetivas: medo, ciúme, raiva, ansiedade, etc. Assim, explica Varela, a palavra emoções é usada aqui num sentido muito específico, isto é: "A tonalidade do afeto que acompanha uma mudança na transparência." (VARELA, 2002, p. 132). E o afeto, por outro lado, é o “[ . . . ] alargamento da orientação disposicional, que será pré-condição para o tom emocional que irá aparecer." (VARELA, 2002, p. 132). Percebemos que o afeto tem aqui dois sentidos distintos: num certo sentido ele é a tonalidade que se expressa numa emoção específica, e no outro, ele é alargamento, abertura ou criação de uma disposição, pré-condição para a emoção que irá surgir. Concluo, a partir dessa explicação que, se por um lado o afeto cria condições para a chegada de uma emoção específica, por outro, se expressa nessa mesma emoção enquanto uma determinada tonalidade afetiva. Ou seja, o afeto não apenas cria

80 conceito de acoplamento estrutural foi desenvolvido por F. Varela e H. Maturana (2003) para explicitar o processo de mútua especificação entre o ser vivo e o meio. Nessa concepção não é o meio que determina o ser vivo tampouco o vivo que determina o meio, pois não se trata de uma interação instrutiva. Meio e ser vivo são fontes recíprocas de perturbação um para o outro; se houver compatibilidade entre ambos, haverá um processo contínuo de mudanças mútuas de estado.

9 Prontidão ontológica no sentido de se estar mobilizado para entrar no fluxo de acordo com a situação que irá se apresentar, tal como um caçador que fica à espreita. Preferimos manter a expressão no original por ter sido criada pelo autor. as condições para a emoção, como permanece enquanto tonalidade virtual nas emoções específicas, podendo se bifurcar em outras tonalidades e emoções. E Varela exemplifica:

Tenho uma disposição (dispositional attitude) que me engaja numa antecipação de escrever e modelar meu pensamento em sentenças. Enquanto escrevo essa palavra agora, a disposição é preenchida por uma carga emocional, um ressentimento moderado por não encontrar a expressão apropriada (VARELA, 2002, p. 132)

$\mathrm{O}$ afeto como tendência disposicional (dispositional trend) é uma predisposição para o que irá ocorrer, ocasionando uma possível mudança nesse tom emocional. É interessante observar aqui que, para Varela, a emoção está sempre acompanhada de uma franja afetiva, numa abertura para a diferenciação e num movimento incessante.

O papel do afeto no automovimento do fluxo será, portanto, explorado por Varela com o tema da protensão, na medida em que, para ele, a consciência é constituída pelo tempo enquanto afeto de si por si, ou ainda, no afetarse por algum outro, na experiência da alteridade. Se por um lado o afeto é constitutivo do self, ao mesmo tempo contém uma radical abertura, ou um inesperado em relação ao que irá ocorrer (VARELA, 1997). Varela cita J. Brought ao comentar Husserl, que afirma que, se o infinito horizonte é aberto por um fluxo absoluto, nós mudamos ao acumular o passado, enquanto paradoxalmente permanecemos o mesmo. Mas para isso deve haver uma fissura na consciência: "Se minha consciência interna estivesse colada sem fissura as minhas experiências passageiras, a passagem do tempo estilhaçaria meu ego em fragmentos" (apud VARELA, 2002, p. 130). Embora nesse comentário sobre Husserl ainda se trate de um ego, vemos que a concepção de consciência já começa a se modificar. A consciência não pode ser uma entidade, substância fechada se a concebemos como imanente ao fluxo temporal, numa disposição afetiva para acolher o novo. É na dinâmica do fluxo enquanto protensão que Varela se baseia para fazer uma análise genética da temporalidade.

\section{A Dinâmica do Presente na Microtemporalidade}

Varela continuará esse trabalho juntamente com a filósofa Natalie Depraz, colocando como objetivo principal a investigação da estrutura 
dinâmica do momento presente em seu eixo afetivo imediato e microtemporal. Os autores procuram descrever "[ . . . ] o movimento de flutuação original, o ritmo assimétrico primário que está no coração de nossa experiência do tempo." (VARELA; DEPRAZ, 2000, p. 149). Esse papel constitucional do afeto, como foi dito, é um caminho que foi aberto por Husserl quando, por volta de 1920, ultrapassando sua fenomenologia estática do tempo, procura uma orientação genética. Essa reviravolta em sua teoria lhe permitiu tratar o tema de forma mais nítida e aguçada, pois sua concepção do tempo deixa de ser predominantemente formal e abstrata como havia sido estabelecida nas Lições ${ }^{10}$

Varela e Depraz (2000) seguem alguns de seus insights em Experiência e Julgamento. Se Husserl deixou de lado, em um primeiro momento, o afeto nas suas análises sobre a consciência temporal - em oposição a James, que fez do corpo a causa primeira das emoções - , seu último trabalho o conduz a situar o afeto na origem do fluxo temporal. Entretanto, afirma Varela, suas análises permanecem limitadas, uma vez que ele não precisa qual é o papel desempenhado pelo afeto, permanecendo abstrato. A proposta de Varela e Depraz (2000) é dar corpo a esses insights trazendo o elemento afetivo para o momento presente das emoções vividas.

Os autores consideram fundamental um trabalho empírico de forma a trazer tais análises para o concreto. Para isso, eles baseiam-se em abordagens específicas das emoções vividas. Partem do princípio de que as disposições emocionais são inseparáveis de nossa história como ser vivo, levando em consideração tanto a biologia evolutiva, quanto a neurociência e analisando os micro-eventos no funcionamento de nossa fisiologia cerebral.

Propõem um duplo gesto metodológico para esse trabalho empírico. Inicialmente, fazem uma análise fenomenológica re-enagida (re-enacted) da experiência, para analisá-la no domínio propriamente experiencial, e não apenas descritivo. Partindo do conceito de enação formulado por Varela - que propõe uma inseparabilidade entre ser e fazer - o agir no mundo en-age, ou seja, a ação sobre o mundo já é

10 Essa concepção temporal abstrata e desencarnada foi motivo para as críticas de Merleau-Ponty em Fenomenologia da Percepção. uma ação sobre si, uma autoconstituição. Essa análise da experiência revela o papel da valência. A valência afetiva pode ser compreendida como o afeto imediato que surge de algo que nos toca, enquanto atração ou repulsão, e que provoca em seguida emoções diferenciadas: como a alegria de ouvir uma bela música, ou a tristeza de ver um parente partir; o prazer de encontrar um amigo que há muito não se via, ou a dor de encontrar o amado nos braços de outra. É o invariante constitucional da emoção primordial, e é, nela mesma, fonte de variação, uma flutuação. Cabe ressaltar a noção de invariância em algo que se constitui como a própria potência de variação, ou seja, essa valoração primordial que é a valência afetiva.

O principal insight que recuperam de Husserl é a manifestação primária do afeto como produtora de contornos e orientações fundamentais do mundo: "Essa descoberta fundamental da análise genética coloca-nos perfeitamente no caminho da inseparabilidade entre afeto e cognição, entre valores e a vida nela mesma." (VARELA; DEPRAZ, 2000, p. 147). Assim, é com a força afetiva que o mundo ganha forma e se manifesta como relevo, que ao se projetar forma um contraste que nos desperta, como sob um golpe. "[ . . . ] sou afetado por algum dado sensorial, atraído por alguma tendência afetiva que me habilita a me orientar receptivamente no espaço e no mundo. Em outras palavras, seja o que for que me afete, não posso ter uma experiência crua como protoimpressões ou impactos (Uraffektion)." (VARELA; DEPRAZ, 2000, p. 147). Mesmo a primeira aparição já é invadida por tendências afetivas, num mundo esboçado pré-egoicamente.

Os afetos são de imediato, um preenchimento ou um esvaziamento, um aumento ou uma diminuição. Podemos perceber como no mundo dos cegos os afetos auditivos e táteis se desenvolvem e se aguçam se tornando uma fonte de referência importante para sua orientação no mundo. A percepção, portanto, está entrelaçada com o mundo afetivo, como uma forma de orientação, de ação pré-formada, e toda ação já faz parte do mundo construído por cada um a partir dos impactos afetivos que nos despertam, como sob um golpe.

Embora Varela e Depraz (2000) utilizem o termo receptividade, uma consciência préreflexiva está em ação. Esta é uma dimensão ativa e passiva ao mesmo tempo. De saída o mundo já me toca, possui relevo, rugosidades, 
sendo segmentado de acordo com uma perspectiva afetiva. Surge, daí, a inseparabilidade entre o domínio cognitivo e afetivo.

O próximo passo metodológico será então fazer uma análise progressiva, ou seja, examinar tanto na neurociência como na biologia evolutiva o surgimento e desenvolvimento desse invariante na vida animal. Baseados nessas observações, concluem que a emergência do momento presente surge de um germe de disposição para o movimento, ou de uma flutuação primordial. Embora Varela recorra à biologia evolutiva para fundamentar sua teoria, ele se diferencia de certa forma, das análises darwinianas, porque o que procura como invariante não são as expressões das emoções em homens e animais. O que ele busca como invariante é a própria variação.

A análise da estrutura dinâmica do momento presente será feita a partir de um tempo mínimo, ou numa microtemporalidade (milésimos de segundos). A dinâmica do afeto participa do processo cognitivo nessa espessura microtemporal. Nesta direção apontam uma dinâmica temporal corporificada, em que há um coengendramento entre o domínio emotivo e cognitivo, a partir desse nível afetivo imediato ou microtemporal. O agente cognitivo não pode mais ser concebido aqui como um si formal ou não afetivo, e as emoções como o colorido que viria sobrepô-lo. Tal dinâmica afetiva se desdobrará de uma só vez, tanto em um leque de emoções, quanto numa intencionalidade cognitiva.

O termo afetivo é utilizado aqui num sentido genético, ou seja, como inconsciência ou afetividade primária. Embora genética, a afetividade coexiste com as emoções e com os conteúdos reflexivos propriamente ditos, uma vez que essa gênese é contínua e ininterrupta, imersa no fluxo temporal.

\section{A Afetoemotividade na Constituição do I ndivíduo}

Gilbert Simondon formula uma teoria das emoções que traz ressonâncias com a concebida por Varela e Depraz. Para Simondon (1989) o sujeito comporta duas dimensões, uma individuada e uma pré-individuada. Essa carga de realidade pré-individual é indeterminada e co-presente a todo o momento no indivíduo. A afetoemotividade ocorre nessa relação do individuado com o pré-individual, produzindo desvios e variações:

[ . . . ] prazer e dor, tristeza e alegria são os intervalos extremos em torno dessa relação entre o individual e o pré-individual no ser sujeito, não é preciso falar de estados afetivos, mas antes de trocas afetivas, trocas entre o pré-individual e o individuado no ser sujeito. A afetoemotividade é um movimento entre o indeterminado natural e o hic et nunc da existência atual (SIMONDON, 1989, p. 106).

As trocas afetivas entre o indivíduo e o préindividual no sujeito ocorrem num movimento contínuo assegurando a potência inventiva e transformadora deste. Essas trocas produzem não apenas prazer e alegria, tristeza e dor, que são polaridades extremas, mas uma diversidade de momentos afetivos, que se expressam em estados mais ou menos alegres. Normalmente acreditamos que o prazer e a dor significam um acontecimento que nos afeta de forma favorável ou desfavorável para a vida. Mas não é apenas no ser individuado que essa dor ou prazer existem, pois dificilmente eles são de ordem puramente somática. A relação entre o pré-individual e o individual pode determinar um estado afetivo positivo ou negativo no sujeito. O estado afetivo positivo ocorre quando há sinergia da individualidade constituída com o movimento de individualização atual do préindividual. O estado afetivo negativo, ao contrário, indica estados de conflito entre esses dois domínios do sujeito (SIMONDON, 1989).

Simondon (1989) utiliza o vocábulo afetoemotividade por considerar que afeto e emoção são inseparáveis. O afeto precede e segue a emoção numa circularidade imanente. Ele entende a afetoemotividade como um bloco que se diferencia: por um lado a afetividade, que contém uma carga de realidade pré-individual, por outro a emotividade, que se resolve numa ação emotiva que exprime essa afetividade. Entretanto, a emotividade não esgota essa carga não individuada ou afetiva. Parece, num primeiro momento, que a afetividade seria o plano de emergência da emotividade, o solo que a constitui, já que o afeto é pré-individual. Mas é a emoção que unifica e significa a afetividade, precisando para isso do coletivo: “O coletivo é necessário para que a emoção se atualize." (SIMONDON, 1989, p. 116). A emoção é, portanto, a vertente ativa e movente da afetividade. A dimensão afetiva inicial não poderia se realizar completamente no sujeito sem a intervenção do coletivo: “Existe na afetividade uma pré-emotividade permanente.." (SIMONDON, 1989, p. 116). Assim, afe- 
to e emoção se co-determinam na medida em que a emoção penetrada de coletivo significa e unifica a afetividade. O coletivo não é para Simondon sinônimo de social, que se oporia ao indivíduo, tal como compreendido pela psicologia social clássica. O indivíduo e o coletivo são pólos de uma relação única que é a relação transindividual. Nem o coletivo é uma instância totalmente exterior ao indivíduo, nem o indivíduo é uma instância totalmente fechada sobre si mesma. O transindividual diz respeito à intercessão ou ao cruzamento entre a relação de si para consigo e a relação de si para com o mundo. Na medida em que somos constituídos por essa carga de realidade préindividual, quando entramos em relação com o outro e com o coletivo, estamos entrando em relação com essas realidades pré-individuais e não com os indivíduos enquanto realidades fechadas sobre si mesmas. Dessa forma o sujeito e sua realidade psíquica, bem como o coletivo, não são fechados sobre si mesmos. A problemática psíquica não se resolve de maneira intra-individual, nem interindividual. Nas relações interindividuais, que constituem, na verdade, a maior parte das relações sociais, o indivíduo entra em relação com os outros e se percebe como personagem através da representação funcional que o outro faz dele (EScóssıA, 2004).

Mas não é enquanto personagem representado pelo outro, nem por si mesmo, que acedemos a essa realidade, que ao fazer contato com a alteridade nos transfigura e nos mobiliza. É a parte pré-individual do sujeito que o faz voltar-se para o coletivo, tendendo para ele como forma de resolver essa tensão afetiva que o transforma, pois sua resolução só pode ser encontrada no coletivo. Dessa forma, tal como na proposta da teoria da enação em Varela, sujeito e mundo se co-determinam; e a co-determinação entre afetos e emoções ocorrerá tendo em vista esse nível de indeterminação do pré-individual.

A emoção se caracteriza, portanto, em Simondon (1989), como uma individuação sempre em via de se realizar, enquanto a afetividade precede e acompanha a emoção, pois é ela que perpetua no sujeito a possibilidade de sua individuação, na medida em que conduz essa carga de natureza pré-individual. A emoção, por outro lado, enquanto ligada à ação, assume a afetividade e se coloca como o ponto de inserção dessa pluralidade afetiva em uma unidade de significação. O sujeito, nessa concepção, supõe um indivíduo e uma realidade pré-individual, um campo portador de singularidades. É o indivíduo enquanto significação efetuada, enquanto portador da expressão emotiva, que se traduz em coletivo: "O espaço entre o individual e o social constitui o universo transindividual: nem interior nem exterior ao indivíduo, mas espaço limite entre exterioridade e interioridade, um fora interior, cuja relação com o indivíduo é de prolongamento e não de oposição." (ESCÓSSIA, 2004, p. 103).

O acesso a esse campo singular se dá, portanto, pela via afetiva. Tal acesso permite ao indivíduo se defasar ${ }^{11}$ ou se deslocar em relação a si mesmo e se transformar. E a emoção é a expressão desse movimento na medida em que dá a ele uma significação.

\section{A Constituição Cognitiva e Emotiva do Sujeito no Plano Afetivo}

A partir da análise da consciência em James e Husserl foi possível para Varela percorrer algumas pistas para adentrar no domínio afetivo. Como foi visto, ele compreende a consciência como composta por três níveis temporais distintos. O primeiro é o utilizado pela psicologia experimental e refere-se a objetos e eventos no mundo. Nesse nível o tempo é linear como o tempo de um relógio, subdividido em partes iguais, e por isso não possui qualidade nem espessura. O segundo decorre de um ato de redução fenomenológica, conhecido como tempo interno aos atos de consciência. Mas o nível temporal propriamente afetivo se encontra no mais elementar da consciência, onde não há mais distinção entre interno e externo, pois é um puro fluxo de consciência sem sujeito, ou como afirma Husserl, o tempo absoluto constituindo fluxos de consciência. Varela segue a pista de Husserl, entretanto quer pensar o afeto no corpo, sem afastá-lo do nível experiencial e pragmático. James traz então uma contribuição importante, pois consegue abordar o tempo na textura própria à experiência e não apenas no nível teórico. Inicialmente aborda dois níveis de consciência, um puro fluir temporal no sen-

11 Conceito utilizado por Simondon (1989), para quem o sujeito é fasado, ou seja, constituído por fases (individual, pré-individual) que o faz portador de uma diferença interna que o diferencia dele mesmo. 
tido passado-futuro e outro enquanto unidade no presente. A textura que compõe o presente vivo é mais do que uma localização no tempo ou um ponto no espaço, pois possui qualidade, duração, um bloco de espaço-tempo. Um outro tipo de consciência emerge na fase mais filosófica de seu trabalho. Nos Ensaios Sobre o Empirismo Radical, James (1979) quer pensar a realidade no momento em que ela se faz e não após sua constituição. Assim, ele faz um movimento inverso e parte do campo da experiência pura para interpretar as análises psicológicas. A consciência aqui se dilui na experiência, nem subjetiva, nem objetiva, nem interna, nem externa, realidade ao mesmo tempo física e mental, puro plano de composição das forças afetivas. Nesse nível ela inexiste enquanto entidade ou substância fechada.

Varela se apropria do conceito de protensão em Husserl, para, divergindo dele, pensar a dimensão genética afetiva como abertura ao indeterminado, ao novo, e não como uma expectativa previsível. O afeto é então compreendido como abertura à temporalidade, subjacente ao tempo que se expande, e, constitutivo do self.

Numa perspectiva pragmática, enativa, o afeto é pensado como disposição para acolher o novo. O conceito de consciência se amplia para um nível que se descola do ego, e nesse ponto de abertura ela é considerada como imanente ao fluxo temporal.

Varela e Depraz trazem essa pesquisa para o domínio empírico e investigam o eixo afetivo na estrutura dinâmica do momento presente.
Essa análise da experiência revela a valência afetiva, um afeto imediato de atração ou repulsão que surge quando algo nos toca. A valência afetiva surge como a manifestação primária do afeto, produtora de contornos e orientações fundamentais do mundo. A partir dela o mundo ganha forma, valor e sentido. Essa análise genética mostra a inseparabilidade entre afeto, emoção e cognição, entre a vida e as valorações. A dinâmica afetiva em sua flutuação primordial se desdobra nas emoções e nos conteúdos cognitivos que surgem na consciência reflexiva e subjetiva. São os afetos ou intensidades, que ao percorrer o corpo, produzem interpretações.

Embora em contexto teórico diverso encontramos ressonâncias em Simondon com a proposta apresentada por Varela e Depraz. De forma similar à experiência pura em James o transindividual não está nem dentro nem fora do sujeito, mas no limiar, no encontro com o outro, entre o indivíduo e o meio, uma carga afetiva não individuada.

$\mathrm{O}$ afeto conecta o sujeito com a alteridade e o faz diferir de si mesmo. Enquanto genético, se situa num nível prévio à consciência reflexiva, sendo o que possibilita o novo e a inventividade surgir no plano das formas. Pode ser entendido como um plano de onde se desdobram as emoções e as significações que surgem com ela. A emoção unifica essa pluralidade afetiva ao lhe dar um sentido. Essas significações, por sua vez, refluem sobre o plano afetivo, numa circularidade imanente.

\section{Referências}

DEPRAZ, N. Delimitation de l'emotion. Revue de Phénoménologie Émotion et affectivité, Paris, n. 7, p. 121148, 1999.

DUPUY, J.P. Nas Origens das Ciências Cognitivas. São Paulo: UNESP, 1995.

ESCÓSSIA, L. O Coletivo Como Plano de Coengendramento do Indivíduo e da Sociedade. 2004. Tese (doutorado) - Programa de Pós-Graduação em Psicologia, Universidade do Rio de Janeiro, 2004, Rio de Janeiro, BR-RJ.

JAMES, W. Princípios de Psicologia. JAMES, W. In: Ensaios Sobre o Empirismo Radical. São Paulo: Abril Cultural, 1979. (Os Pensadores) Cap. 9. Edição original publicada em 1890.

KASTRUP, V. A Invenção de Si e do Mundo: uma introdução do tempo e do coletivo no estudo da cognição. Campinas: Papirus, 1999.

LAPOUJ ADE, D. William James: empirismo e pragmatismo. Paris: PUF, 1997. 
SIMONDON, G. L'individuation psychique et collective. Paris, Aubier, 1989.

SUTHERLAND, K. Consciousness and Emotion. Journal of Consciousness Studies, Exeter, v. 8, n. 12, p. 79-82, 2001.

VARELA, F. Francisco Varela In: COSTA, R. da (Org.). Limiares do Contemporâneo: entrevistas. São Paulo: Escuta, 1993. P 72 - 97

VARELA, F. The Specious Present: A Neurophenomenology of Time consciousness. 1997. Disponível em: <http://www.ccr.jussieu.fr/varela/human_consciousness/articles.html> Acesso em: 10 de mar de 2004.

VARELA, F. Present-Time Consciousness. J ournal of Consciousness Studies, Exeter, v. 6, n. 2/3, p 111-140, 1999.

VARELA, F. O Desencantamento do Abstrato. In: PÉLBART, P.P.; COSTA, R. da (Org.). Reencantamento do Concreto. São Paulo: Hucitec, 2003. P. 72-86.

VARELA, F.; DEPRAZ, N. At the Source of Time: Valence and the Constitutional Dynamics of Affect. 2000. Disponível em: <www.arobase.to/v4_n1_2/varela.pdf> Acesso em: 05 de fev. de 2002.

VARELA, F.; MATURANA, H. A Árvore do Conhecimento. São Paulo: Palas Athena, 2003.

VARELA, F.; THOMPSON, E; ROSCH, E. A Mente Incorporada: ciências cognitivas e experiência humana. São Paulo: ARTMED, 2003.

Recebido em agosto de 2009

Aprovado para publicação em novembro de 2009

\section{Jerusa Machado Rocha}

Psicóloga do Hospital Azevedo Lima e consultora no Educar em Revista e-mail: jerusar@ig.com.br 